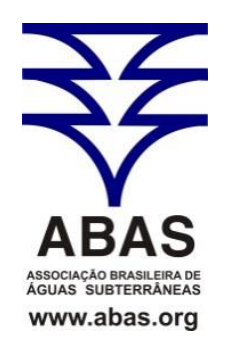

\section{COMPARAÇÃO DA EFICIÊNCIA DAS TÉCNICAS DE BOMBEAMENTO, TPE E DPE PARA REMEDIAÇÃO DE ÁREAS CONTAMINADAS POR HIDROCARBONETOS DE PETRÓLEO}

\author{
COMPARISON OF EFFICIENCY OF PUMPING, TPE AND DPE \\ TECHNIQUES FOR REMEDIATION OF AREAS CONTAMINATED BY \\ PETROLEUM HYDROCARBONS
}

\author{
Patricia Totti ${ }^{1}$; Hung Kiang Chang ${ }^{2}$
} DOI: http://dx.doi.org/10.14295/ras.v30i1.28497

\begin{abstract}
Resumo: Diversas técnicas são utilizadas para a remediação de áreas contaminadas por derivados de petróleo, as quais podem causar severos danos ambientais e à saúde humana. O objetivo deste trabalho é comparar a eficiência de três dessas técnicas: bombeamento, TPE (Two Phase Extraction) e DPE (Dual Phase Extraction), na remediação de uma área contaminada com óleo diesel em Minas Gerais. No Brasil não há estudos semelhantes e este trabalho mostra que o DPE pode ser uma opção viável para reduzir o tempo de remediação. A partir da compilação de dados de sistemas de remediação em operação na área impactada (subdividida em áreas 1 e 2) e da realização de ensaios de campo, foi possível confirmar o aumento significativo das vazões de extração utilizando a técnica de DPE em relação às obtidas com bombeamento e TPE. Para a área 1, o DPE apresentou vazão de extração de líquido 38,5\% maior que a obtida por bombeamento. Na área 2, o DPE apresentou aumentos de 39,68\% a 47,63\% na vazão de líquido em relação ao TPE e de $43,77 \%$ a 51,3\% em relação ao bombeamento. A maior efetividade do DPE em relação ao bombeamento convencional pode ser explicada pelo aumento do gradiente de pressão, que ocasiona maior mobilidade de água e de óleo para o interior do poço. Em relação ao TPE, o DPE também foi mais efetivo, e, neste caso, as maiores vazões de líquido obtidas podem ser explicadas pelo rebaixamento causado pelo bombeamento, somado ao aumento de fluxo devido ao maior gradiente causado pela aplicação do vácuo.
\end{abstract}

Palavras-chave: Remediação. Extração multifásica. Hidrocarbonetos de petróleo. Óleo diesel.

\begin{abstract}
Several techniques are used for the remediation of areas contaminated by petroleum products, which can cause severe damage for environment and human health. The objective of this study is to compare the effectiveness of three techniques: pumping, TPE (Two Phase Extraction) and DPE (Dual Phase Extraction) on the remediation of a contaminated area with diesel in Minas Gerais. In Brazil there are no similar studies and this work is important to show that the DPE may be a viable option to reduce remediation time in a contaminated area. From the compilation of data remediation systems in operation and performing field tests, it was possible to confirm the significant increase in extraction flow using the DPE technique in relation to the flow obtained with pumping techniques and TPE. For area 1, the use of DPE resulted in the extraction liquid flow higher than the 38.5\% compared to that obtained by pumping. In area 2, the use of DPE caused increases of $39.68 \%$ to $47,63 \%$ in the liquid flow relative to the TPE and $43.77 \%$ to $51,3 \%$ in relation to the pumping. The greater effectiveness of the DPE compared to conventional pumping can be explained by the increased pressure gradient, which causes increase in mobility of water and LNAPL into the well. Regarding TPE, DPE was also more effective, and in this case, the highest net flows obtained can be explained by the drawdown caused by pumping, coupled with the increased flow due to the larger gradient caused by the application of vacuum.
\end{abstract}

Keywords: Remediation. Multiphase extraction. Petroleum hydrocarbon. Diesel.

\section{INTRODUÇÃO}

Vazamentos de derivados de petróleo em tanques de estocagem, linhas de processo, dutos, transporte rodoviário ou ferroviário po- dem causar severos danos ambientais e à saúde humana. Em subsuperfície, os combustíveis líquidos são particionados e podem permanecer adsorvidos ou absorvidos no solo, em fase livre, dissolvidos em água subterrânea

1-2 UNESP (ptotti@ hotmail.com, chang@ rc.unesp.br) 
ou em fase vapor (CHARBENEAU, 2006). A fase livre, formada pelo líquido vazado, é uma fonte secundária para a contaminação da água subterrânea e distribuição dos contaminantes para outros meios. Portanto, a remoção da fase livre é o primeiro objetivo de qualquer sistema de remediação.

As técnicas de bombeamento e de extração multifásica (MPE - Multi Phase Extraction) vêm sendo amplamente utilizadas para a remediação de áreas contaminadas por hidrocarbonetos de petróleo e outros compostos voláteis e semi-voláteis.

O histórico de áreas contaminadas, tanto no Brasil quanto nos EUA, demonstra que os sistemas implantados para remediação operam por períodos superiores a 10 anos, e que a eficiência dos mesmos varia ao longo do tempo. De forma geral, os sistemas apresentam eficiência mais elevada no início, decaindo durante a operação. Isto se deve, dentre outros fatores, às diferentes formas de distribuição dos contaminantes em subsuperfície ao longo do tempo. Por esse motivo, a tendência é a utilização de uma segunda técnica ou de técnicas conjuntas de remediação de forma a otimizar a remoção de contaminantes, especialmente em fase livre.

As taxas de remoção dependem do tipo de contaminante, das características geológicas e hidrogeológicas da área, da forma de distribuição do contaminante em subsuperfície, do tipo de sistema de remediação utilizado, entre outros fatores (CHARBENEAU, 2006).

O objetivo deste trabalho é a comparação da eficiência de três técnicas de remediação: bombeamento, TPE (Two Phase Extraction) e DPE (Dual Phase Extraction), aplicadas em uma área contaminada com óleo diesel, para verificar a eficiência desta última em relação às demais.

Observações empíricas em sistemas de remediação em diversas áreas impactadas nos EUA e América Latina, que utilizaram a técnica DPE, apontam um aumento significativo (superior a 30\%) na remoção da massa total de contaminantes com a utilização de DPE em relação ao bombeamento e ao TPE, considerando as taxas de recuperação de massa nas fases livre, dissolvida e vapor. (USEPA, 1997;
2005; MCDOWELL and BARBEE, 2001; SOLC, 2007; RUSZIN, 2012).

No Brasil não há estudos anteriores comparando as três técnicas, possivelmente porque o DPE ainda é muito pouco utilizado no país. Dessa forma, a comparação da eficiência de extração entre estas técnicas, aplicadas a uma mesma área, é importante para mostrar se o DPE, apesar de apresentar maior custo de implantação e operação, pode ser uma opção viável para reduzir o tempo de remediação de uma área contaminada.

A área objeto de estudo foi impactada por um derramamento de óleo diesel em início de 2003, decorrente de defeito em uma linha industrial que operava sob pressão, ocasionando a contaminação de uma extensão de aproximadamente $12500 \mathrm{~m}^{2}$ e gerando uma pluma de fase livre com volume estimado de $300 \mathrm{~m}^{3}$.

A partir de 2003 a área passou por diversas etapas do gerenciamento de áreas contaminadas, tais como investigações preliminar, confirmatória, detalhada e complementar, análise de risco à saúde humana e implantação de sistemas de remediação emergenciais e definitivos (CETESB, 2001). De 2003 a 2014 operaram na área sistemas de bombeamento e TPE, basicamente. Para fins experimentais e comparativos, a área em estudo foi dividida em duas, aqui denominadas área 1 e área 2.

Em outubro de 2014 foi realizado um teste-piloto utilizando as técnicas de bombeamento e DPE na área 1, e em dezembro do mesmo ano foram realizados ensaios de bombeamento, TPE e DPE na área 2, com o objetivo de comparar a eficiência dos três sistemas nos mesmos poços e verificar se o comportamento observado no ensaio-piloto da área 1 se repetia para outros poços na área 2 .

\section{FUNDAMENTAÇÃO TEÓRICA}

MPE é uma denominação genérica para uma categoria de tecnologias de remediação in situ que utilizam vácuo para a extração simultânea de contaminantes em mais de uma fase (vapor, dissolvida e livre), em poços ou trincheiras; pode ser dividida em três técnicas distintas, segundo terminologia definida por 
EPA (1997): DPE (Dual-Phase Extraction), TPE (Two-Phase Extraction) e Bioslurping.

O princípio de funcionamento do MPE é semelhante ao SVE (Soil Vapor Extraction), com a diferença de que este último atua apenas na extração de vapores da zona não saturada, em solos de alta permeabilidade, enquanto o MPE é aplicável para remediação simultânea das zonas saturada e não saturada, com a vantagem adicional de ser aplicável a solos de baixa a moderada permeabilidade (U.S. ARMY, 1999).

No DPE, os vapores provenientes do solo e os líquidos são extraídos do poço em tubulações distintas e por bombas ou compressores radiais distintos. Nesta técnica, uma bomba submersível é introduzida na tubulação do poço para a extração de água subterrânea e fase livre, enquanto outra tubulação é interligada ao cabeçote do poço para a extração de vapores, utilizando um compressor radial ou uma bomba de vácuo para gerar pressão negativa no interior do poço (U.S.ARMY, 1999) (Figura 1). O DPE pode ainda ser subdividido em HVDPE (High Vacuum Dual Phase Extraction) e LVDPE (Low Vacuum Dual Phase Extraction). A diferença entre as duas modalidades é a faixa de vácuo em que operam: o HVDPE opera em uma faixa de vácuo variando de $460 \mathrm{mmHg}$ a $660 \mathrm{mmHg}$, e o LVDPE opera em uma faixa de vácuo de 76 mmHg a 305 mmHg (EPA, 1997).

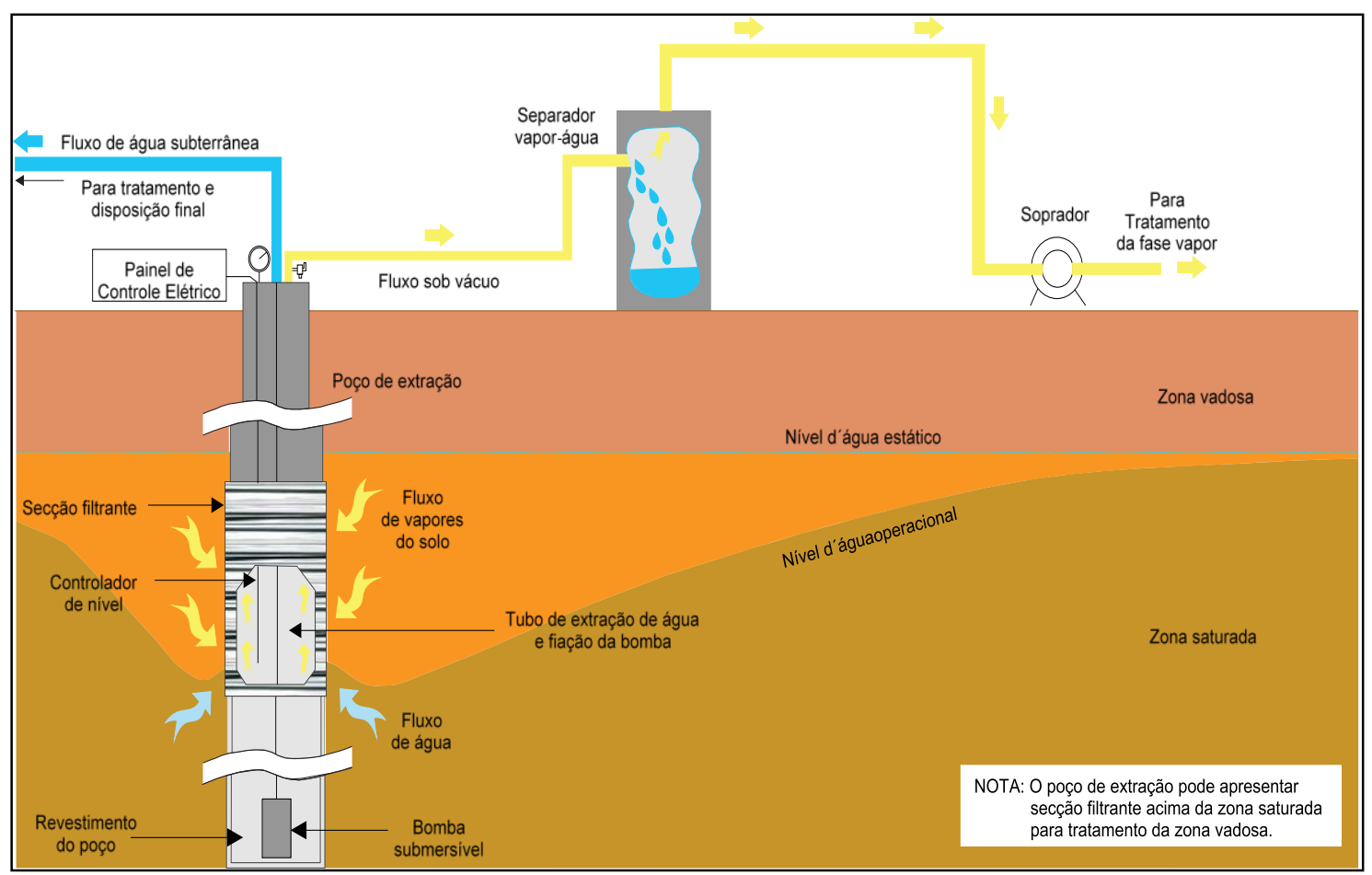

Figura 1 - Diagrama típico de um sistema DPE

Figure 1 - Typical diagram of a DPE system

Fonte: Modificado de EPA (1997)

No TPE, as três fases (vapor, dissolvida e livre) são extraídas na mesma tubulação de sucção, utilizando-se uma única bomba de vácuo ou compressor radial. Nesta técnica, o tubo de sucção é posicionado abaixo do nível d'água e a operação ocorre com alto vácuo (entre $460 \mathrm{mmHg}$ e $660 \mathrm{mmHg}$ ). A turbulência gerada no tubo de sucção facilita a transferência de massa de contaminantes da fase dissolvida para a fase vapor, obtendo-se eficiência de stripping superior a $98 \%$ (o processo de air stripping consiste na transferência de massa da fase aquosa para a fase gasosa) (EPA, 1997) (Figura 2). 


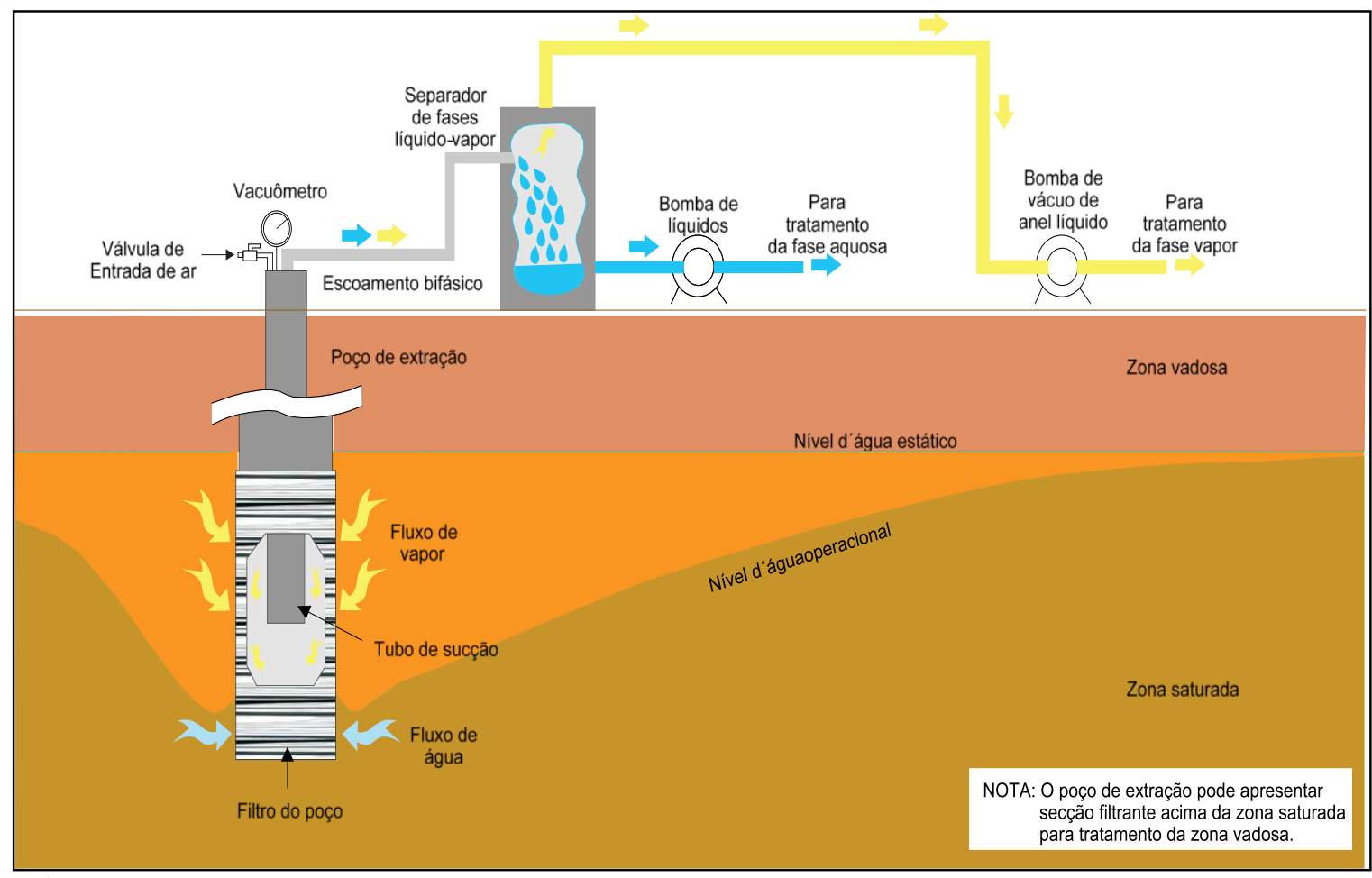

Figura 2 - Diagrama típico de um sistema TPE

Figure 2 - Typical diagram of a TPE system

Fonte: Modificado de EPA (1997)

Os projetos de MPE normalmente são dimensionados de acordo com resultados de ensaios pilotos, ou muitas vezes são estimados de acordo com a experiência dos projetistas (EPA, 1997).

\subsection{Princípios do escoamento multifásico}

Uma simplificação da equação de conservação de massa, quantidade de movimento e energia, aplicada ao fluxo de água subterrânea, é apresentada pela Lei de Darcy, que correlaciona a velocidade da água subterrânea com o gradiente de energia, por meio da equação:

$$
\tilde{q}=K x \tilde{\mathrm{I}}
$$

(1) (CHARBENEAU, 2006)

Onde: $\tilde{q}$ é o fluxo volumétrico; $K$ é a condutividade hidráulica; e Ĩ é o gradiente de energia (gradiente hidráulico) - $\nabla h$.

A condutividade hidráulica depende de propriedades do fluido que ocupa os poros e também das características geométricas do meio poroso, e pode ser generalizada como:

$$
K=\frac{\rho g k}{\mu}
$$

(2) (CHARBENEAU, 2006)

Onde: $\rho$ é a densidade do fluido; $g$ é a constante gravitacional; $k$ é a permeabilidade intrínseca; e $\mu$ é a viscosidade.

A permeabilidade intrínseca dependente apenas das características da matriz porosa.

Uma forma geral da lei de Darcy aplicada a fluxo multifásico pode ser expressa da seguinte forma:

$$
\tilde{q}=-\frac{k}{\mu}(\nabla p+\rho h \hat{k})
$$

(3) (CHARBENEAU, 2006)

Onde: $\widehat{k}=\nabla z$ é o vetor unitário ascendente na direção $\mathrm{z} ; p$ é a pressão do fluido; e $h$ é a carga hidráulica.

Fluidos em meio poroso se movem apenas quando há forças atuando sobre os mesmos; em meio poroso, essas forças se relacionam ao gradiente de pressão e à gravidade.

A força por unidade de massa para a água $\left(\widetilde{\mathrm{F}}_{\mathrm{w}}\right)$ e o óleo $\left(\widetilde{\mathrm{F}}_{\mathrm{o}}\right)$ podem ser expressas como: 


$$
\tilde{F}_{w}=-g \hat{k}-\frac{1}{\rho_{w}} \nabla \mathrm{p}_{\mathrm{w}}
$$

(4) (CHARBENEAU, 2006)

$$
\tilde{F}_{o}=-g \hat{k}-\frac{1}{\rho_{o}} \nabla \mathrm{p}_{\mathrm{o}}
$$

(5) (CHARBENEAU, 2006)

Onde: $\widetilde{F}_{w}$ é a força atuante na fase aquosa; $\tilde{F}_{o}$ é a força atuante na fase oleosa; $g$ é a constante gravitacional; $\rho_{w}$ é a densidade da água; $\nabla \mathrm{p}_{\mathrm{w}}$ é o gradiente de pressão na fase aquosa; $\rho_{o}$ é a densidade da fase oleosa; $\nabla p_{o}$ é o gradiente de pressão na fase oleosa.

A diferença de pressão na interface de separação das fases molhante (água) e não molhante (óleo) é chamada de pressão capilar e é definida por:

$$
p_{c}=p_{n w}-p_{w}
$$

(6) (CHARBENEAU, 2006)

Onde: $p_{n w}$ é a pressão da fase não molhante; e $p_{w}$ é a pressão da fase molhante.

Combinando a definição de capilaridade (6) com a equação (5), obtem-se a equação de Hubbert (7):

$$
\tilde{F}_{o}=-g \hat{k}-\frac{\nabla p_{c}}{\rho_{o}}+\frac{\rho_{w}}{\rho_{o}}\left(\tilde{F}_{w}+\mathrm{g} \hat{k}\right)
$$

(7) (CHARBENEAU, 2006)

$$
\tilde{I}_{w}=-\nabla \mathrm{h}_{\mathrm{w}}=-\hat{k}-\frac{\nabla p_{w}}{\rho_{w} g}
$$

(8) (CHARBENEAU, 2006)

$$
\tilde{F}_{w}=-g \tilde{I}_{w}
$$

(9) (CHARBENEAU, 2006)

Onde: $\tilde{I}_{w}$ é o gradiente de energia na fase aquosa.

Assumindo que a pressão capilar pode ser negligenciada, tem-se:

$$
\tilde{F}_{o}=-\left(\frac{\rho_{w}}{\rho_{o}}-1\right) g \hat{k}-\frac{\rho_{w}}{\rho_{o}} g \tilde{I}_{w}
$$

(10) (CHARBENEAU, 2006)

A equação (10) mostra que a migração de óleo é controlada pela influência da flutuação (primeiro termo à direita) e pelo gradiente hidráulico associado ao movimento da água (segundo termo à direita).

Em fluxo multifásico e regime estacionário, o fluxo dos fluidos praticamente independem um do outro, pois a interface está situada na zona capilar, onde não há fluxo. A forma análoga da Lei de Darcy para uma fase i é dada pela seguinte equação:

$$
\widetilde{q}_{\imath}=\frac{K_{e i}}{\mu_{i}}\left(\nabla p_{i}+\rho_{i} g \hat{k}\right)
$$

(11) (CHARBENEAU, 2006)

Onde: $\widetilde{q_{l}}$ é o fluxo volumétrico da fase $\mathrm{i} ; k_{e i}$ é a permeabilidade efetiva; $\mu_{i}$ é a viscosidade da fase i; $p_{i}$ é a pressão da fase i; e $\rho_{i}$ é a densidade da fase $i$.

A forma da equação (11) é idêntica à Lei de Darcy aplicada à zona saturada por água, porém no lugar da permeabilidade intrínseca $\mathrm{k}$ utiliza-se a permeabilidade efetiva $\mathrm{k}_{\mathrm{ei}}$. A permeabilidade efetiva pode ser escrita como função da pressão capilar e também é comumente expressa como uma fração da permeabilidade intrínseca do meio, definindo a permeabilidade relativa para a fase $\mathrm{i}\left(k_{r i}\right)$ como:

$$
k_{r i}=\frac{k_{e i}}{k}
$$

(12) (CHARBENEAU, 2006)

E a lei de Darcy pode ser reescrita como:

$$
\widetilde{q_{l}}=\frac{k k_{r i}}{\mu_{i}}\left(\nabla p_{i}+\rho_{i} g \hat{k}\right)
$$

(13) (CHARBENEAU, 2006)

Apesar da forma da Lei de Darcy ser semelhante à utilizada somente para fluxo de água subterrânea, o significado físico da equação 13, utilizando a permeabilidade relativa, é diferente e mais complexo, por causa dos efeitos da histerese na curva de pressão capilar $\left(e m h_{i}\right.$ e $\left.k_{r i}\right)$, sendo função não linear das saturações das fases presentes.

Em sistemas multifásicos, parte dos poros estará saturada com água, parte com NAPL e parte com ar. A soma da saturação destas três fases será 1 . 


$$
S_{w}+S_{o}+S_{a}=1
$$

(14) (CHARBENEAU, 2006)

Onde: $S_{w}$ é a saturação de água; $S_{o}$ é a saturação de óleo; $S_{a}$ é a saturação de ar.

Se os líquidos (água e NAPL) são assumidos como fluidos incompressíveis, a equação da continuidade para a fase $\mathrm{i}$ pode ser escrita como:

$$
n \frac{\partial s_{i}}{\partial t}+\nabla \cdot \tilde{q}_{i}=0
$$

$\mathrm{Ou}$

(15) (CHARBENEAU, 2006)

$$
n \frac{\partial s_{i}}{\partial t}=\nabla \cdot\left(\frac{k k_{r i}}{\mu_{i}}\left(\nabla p_{i}+\rho_{i} g \hat{k}\right)\right)
$$

(16) (CHARBENEAU, 2006)

Onde: $n$ é a porosidade total; e $S_{i}$ é a saturação da fase $i$.

A combinação das equações 14 e 16 com as funções de pressão capilar de cada fase e com as funções de permeabilidade relativa adequadas fornecem um modelo matemático para fluxo em sistemas multifásicos. Mesmo soluções aproximadas para essas equações requerem técnicas de simulação numérica avançada.

\subsection{Geologia Local}

A área objeto de estudo, localizada em Betim - MG, insere-se no contexto geológico do Cráton São Francisco, sob o domínio do Complexo Belo Horizonte, localizado ao norte do Quadrilátero Ferrífero. Estas rochas compõem o embasamento arqueano da região do Quadrilátero Ferrífero, juntamente com outros complexos metamórficos (Bonfim e Bação) e uma sequência do tipo greenstone belt, pertencentes ao Supergrupo Rio das Velhas. O Complexo Belo Horizonte é constituído por um gnaisse bandado, migmatizado, exibindo estrutura schlieren ou estromática e frequentes enclaves máficos, além de corpos granitoides intrusivos (MACHADO, 2010).

O Domínio do Complexo Belo Horizonte está inserido na unidade geomorfológica da Depressão de Belo Horizonte, a qual possui um relevo caracterizado por espigões, colinas de topo plano a arqueado, e encostas policonvexas de declividades variadas nos flancos dessas feições e nas transições. As drenagens mostram um controle estrutural, e se superimpõem ao fraturamento do substrato arqueano (MACHADO, 2010). A Figura 3 apresenta o mapa geológico regional com a indicação da área estudada.

Conforme resultados das diversas sondagens, com profundidade máxima de $15 \mathrm{~m}$, realizadas na área de estudo por empresas de consultoria, os estratos existentes na área foram interpretados, do topo para a base, como: aterro constituído por solo areno-siltoso a silto-arenoso; aterro de solo silto-arenoso a silto-argiloso com fragmentos de materiais de construção e fragmentos de rocha; solo arenosiltoso a areno-argiloso, de coloração avermelhada, apresentando fragmentos subangulosos de quartzo, nódulos argilosos, seixos subangulosos de quartzo; solo arenoso de coloração bege; solo areno-argiloso de coloração cinza esverdeada; areia fina de coloração cinza esverdeada.

$\mathrm{Na}$ área estudada, o aquífero é livre, raso, de grande extensão, sendo constituído por material poroso de alteração do Complexo Belo Horizonte. A recarga desse aquífero ocorre predominantemente por infiltração de águas de chuvas incidentes sobre o solo.

Os resultados obtidos de ensaios de permeabilidade realizados em nove poços indicaram valores de condutividade hidráulica de $7,85 \times 10^{-6} \mathrm{~cm} / \mathrm{s}$ a $1,62 \times 10^{-4} \mathrm{~cm} / \mathrm{s}$, com valor médio de $6,70 \times 10^{-5} \mathrm{~cm} / \mathrm{s}$. O nível d'água médio do lençol freático local é de $6,23 \mathrm{~m}$, variando entre $0,45 \mathrm{~m}$ e $12,90 \mathrm{~m}$. Neste trabalho foi considerada a porosidade efetiva para sedimentos areno-siltosos a silto-arenosos, variando de $10 \%$ a $25 \%$ para o aquífero local, de acordo com informações obtidas de literatura (FETTER, 1994).

Os poços da área 1 estão em uma porção mais alta e relativamente plana do terreno, enquanto os poços da área 2 encontram-se na porção em declive e próxima a um canal de drenagem. A velocidade aparente de fluxo da água subterrânea foi estimada em 8,0 m/ano para a área 1 e 6,5 m/ano para área 2. 


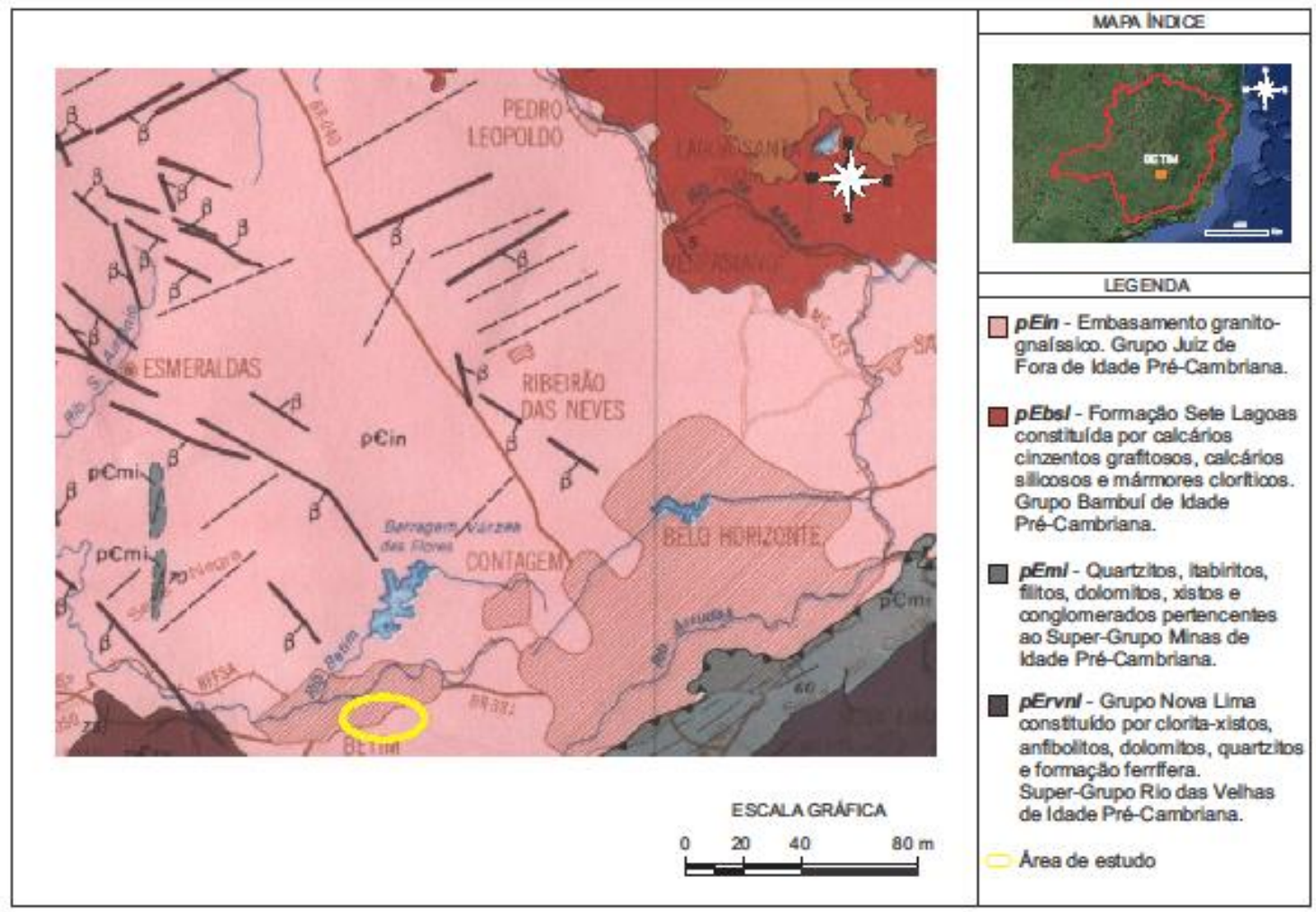

Figura 3 - Mapa Geológico Regional

Figure 3 - Regional Geological Map

Fonte: Modificado de Machado (2010)

No período compreendido entre 2011 a 2014, as concentrações médias de benzeno, principal composto de interesse, em água subterrânea, variaram de $196 \mu \mathrm{g} / \mathrm{L}$ a $18 \mu \mathrm{g} / \mathrm{L}$, permanecendo abaixo do limite de detecção em julho de 2014. As concentrações de TPH variaram de $225328 \mu \mathrm{g} / \mathrm{L}$ a $36721 \mu \mathrm{g} / \mathrm{L}$ e as concentrações de tolueno, etilbenzeno e xilenos permaneceram abaixo dos respectivos limites de detecção no período considerado.

\section{METODOLOGIA}

A comparação entre as técnicas de remediação por bombeamento, TPE e DPE foi feita a partir de resultados operacionais obtidos em sistemas de remediação instalados em uma área industrial localizada às margens da Rodovia Fernão Dias, no município de Betim - MG, e por ensaios-piloto das três técnicas realizados na mesma área.

As áreas 1 e 2 foram submetidas a estudos distintos, desde junho de 2011: na área 1 opera um sistema de bombeamento e tratamento interligando dez poços; na área 2 opera um sistema TPE interligando oito poços. Estes sistemas foram implantados por empresas de consultoria e permaneceram desligados durante os testes para não interferir nos resultados. No entanto, vários equipamentos destes sistemas foram utilizados para compor os sistemas de teste, acrescentando-se outros equipamentos e instrumentos necessários.

$\mathrm{Na}$ área 1, o sistema de bombeamento existente é composto por um compressor que fornece ar comprimido para dez bombas pneumáticas instaladas no interior dos poços. $\mathrm{O}$ controle da vazão e pressão de ar comprimido é realizado por válvulas reguladoras providas de manômetros, instaladas em um painel. $\mathrm{O}$ efluente bombeado é encaminhado para uma caixa separadora água-óleo, onde ocorre a remoção da fase livre, a qual é armazenada em tambores e posteriormente destinada a co-processamento. A água é transferida por uma bomba de fuso para um conjunto de duas colunas de adsorção preenchidas com carvão ativado; nessas colunas ocorre a remoção dos compostos orgânicos, e o efluente tratado é encaminhado para um tanque de estocagem e 
posteriormente enviado por caminhões tanque à uma estação de tratamento de efluentes externa.

Na área 2, o sistema TPE existente é composto por uma bomba de vácuo, interligada a um tanque de equalização e separação de líquidos, ao qual oito poços de extração estão interligados por meio de tubulações rígidas e também por mangueiras. Cada poço de extração é equipado com um cabeçote de vedação, no qual é inserido o tubo extrator. $\mathrm{O}$ vácuo gerado pela bomba de vácuo é a força motriz para a extração multifásica (fases livre, dissolvida e vapor) nos poços. Os fluidos extraídos pelo tubo extrator instalado em cada um dos poços interligados ao sistema são transferidos para o tanque de separação de líquidos, onde ocorre a separação das fases líquida e gasosa. A fase gasosa é transferida para colunas de adsorção em carvão ativado e o vapor tratado é lançado na atmosfera. A fase líquida, composta por água e óleo, é encaminhada para uma caixa separadora água-óleo. A fase oleosa separada é armazenada em tambores e enviada para co-processamento e a fase aquosa, é encaminhada para duas colunas de adsorção em carvão ativado, dispostas em série, nas quais são removidos os compostos orgânicos. Após o pré-tratamento, a fase aquosa é armazenada em um tanque e posteriormente enviada para finalização do tratamento em uma estação de tratamento de efluentes externa.

O vácuo aplicado ao sistema é controlado indiretamente por inversor de frequência acoplado ao motor da bomba de vácuo. Todo o sistema é controlado por um CLP (controlador lógico programável) instalado em um painel de controle.

A Figura 4 apresenta a subdivisão da área e a localização dos sistemas de remediação implantados.

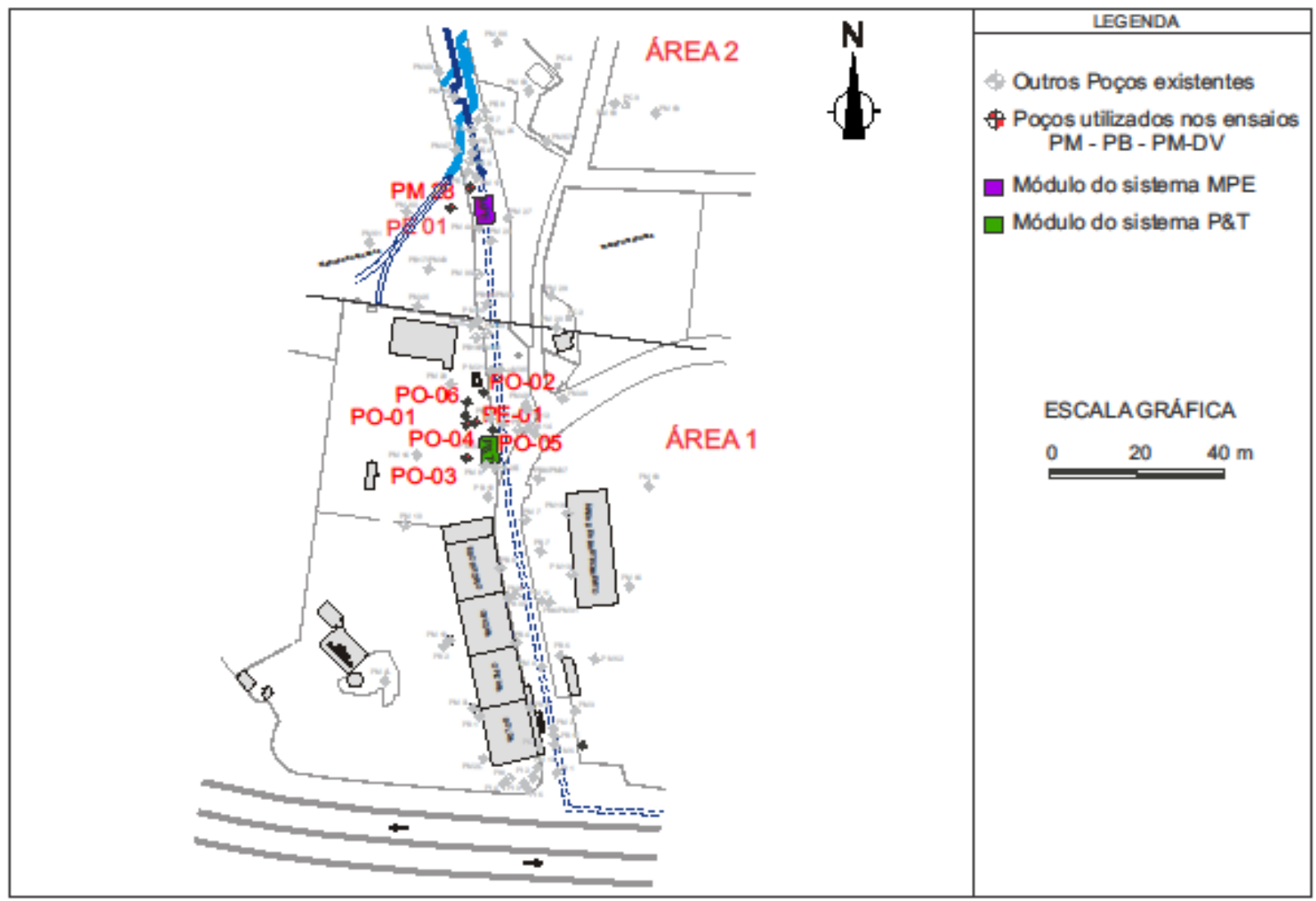

Figura 4 - Localização das áreas 1 e 2 e dos sistemas de remediação implantados

Figure 4 - Location of Areas 1 and 2 and active remediation systems

Fonte: Elaborado pela autora com dados de relatórios de operação de empresas de remediação 


\subsection{Compilação de dados de operação de sistemas de remediação}

Foram analisadas e compiladas informações contidas em relatórios técnicos de trabalhos de investigação e remediação ambiental, realizados no período de 2003 a 2014, por quatro empresas de consultoria que atuaram na área de estudo, com o objetivo de verificar as taxas de extração água/óleo no decorrer desse período.

No sistema de bombeamento, durante o período considerado, foram monitorados os volumes de água subterrânea extraída (totalizados por meio de um hidrômetro), o tempo de operação (por meio de um horímetro instalado no painel de controle), o volume de óleo recuperado e a concentração dos compostos de interesse (BTEX, TPH e PAH) na fase aquosa, por meio de análises químicas realizadas mensalmente nos efluentes do sistema de remediação.

No sistema TPE, o monitoramento da fase aquosa foi idêntico ao realizado para o sistema de bombeamento. Para a fase gasosa, as vazões de extração foram estimadas indiretamente por meio da curva de operação da bomba de vácuo, e foi monitorada mensalmente a concentração de VOC (compostos orgânicos voláteis) com instrumentação portátil.

Nos poços de monitoramento de ambos os sistemas foram medidos mensalmente os níveis de água e de óleo e, trimestralmente, foram realizadas amostragem de água subterrânea em baixa vazão para análises químicas dos contaminantes de interesse (BTEX, PAH, TPH).

\subsection{Ensaios de campo e comparação da eficiência das técnicas de remediação}

$\mathrm{Na}$ área 1 foi realizado ensaio-piloto utilizando as técnicas de bombeamento e DPE e na área 2 foram conduzidos ensaios-piloto de bombeamento, TPE e DPE.

A comparação da eficiência das três técnicas de remediação foi feita por meio dos dados de vazão de extração de água subterrânea, obtidos durante os ensaios de campo.

Para a realização do ensaio-piloto de DPE na área 1 foram utilizados o compressor e o sistema de tratamento de efluentes do sistema de bombeamento previamente instalado na área, além de um sistema móvel de Extração de Vapores do Solo, SVE, para geração de vácuo no cabeçote do poço de extração.

Um poço que apresentou histórico de constante presença de fase livre e está localizado próximo ao centro da pluma de fase livre foi selecionado como poço de extração (PE). $\mathrm{O}$ poço também apresentava características construtivas apropriadas para o uso no ensaio. Três poços de observação (PO-01 a PO-03) foram dispostos radialmente em relação ao poço de extração, em ângulos de $120^{\circ}$ entre si, distanciando-se do PE em $5 \mathrm{~m}, 10 \mathrm{~m}$ e $15 \mathrm{~m}$, de modo a se obter pontos representativos para o monitoramento e detectar eventuais heterogeneidades da área. Além desses, foram utilizados também para observação outros três poços de monitoramento existentes na área, situados a 3,7 m, 6,4 $\mathrm{m}$ e 7,7 $\mathrm{m}$ do PE.

O Quadro 1 apresenta relação de poços utilizados no ensaio da área 1 e as distâncias dos poços de observação em relação ao poço de extração. 
Quadro 1 - Relação de poços utilizados no ensaio-piloto de DPE na área 1

Table 1 - List of wells used in DPE pilot test of area 1

\begin{tabular}{|c|c|c|}
\hline TAG & Tipo de Poço & $\begin{array}{c}\text { Distância em relação ao poço de ex- } \\
\text { tração PE (m) }\end{array}$ \\
\hline PE-01 & poço de extração (PM-15) & - \\
\hline PO-01 & poço de observação (PM-DV-31) & 5 \\
\hline PO-02 & poço de observação (PM-DV-32) & 10 \\
\hline PO-03 & poço de observação (PM-DV-33) & 3,7 \\
\hline PO-04 & poço de observação (PB-11) & 6,4 \\
\hline PO-05 & poço de observação (PM-36) & 7,7 \\
\hline PO-06 & poço de observação (PM-32) & \\
\hline
\end{tabular}

Fonte: Elaborado pela autora

O ensaio de DPE na área 1 foi conduzido durante cinco dias consecutivos, em duas etapas: teste escalonado e teste contínuo.

A etapa de teste escalonado consistiu na aplicação de duas faixas de vácuo distintas no cabeçote do poço de extração (100 e 200 $\mathrm{mmHg}$,), com duração de $2 \mathrm{~h}$ em cada faixa, simultaneamente ao bombeamento com bomba pneumática de deslocamento positivo (tipo auto pump) instalada no mesmo poço, e monitoramento dos seguintes parâmetros: vazões de extração de água, de produto e de vapores; vácuo aplicado no sistema e nos cabeçotes do poço de extração e dos poços de observação; variação do nível d'água no poço de extração e nos poços de observação, utilizando transdutores de pressão; concentração expedita de VOCs nos vapores extraídos; concentração dos compostos de interesse (BTEX, TPH e PAH) nos efluentes líquidos e gasosos, por meio de análises químicas. Foi coletada uma amostra de efluente no final de cada dia de teste, totalizando cinco amostras.

Posteriormente foi realizado o teste de bombeamento para verificar as vazões de extração de água subterrânea sem a aplicação de vácuo no PE durante o período da manhã (das $10 \mathrm{~h}$ às $12 \mathrm{~h}$ ). No período da tarde (das $14 \mathrm{~h}$ às 16h), testou-se novamente o DPE (bombeamento mais aplicação de vácuo no cabeçote do poço de extração). Nessa etapa foram monitorados os mesmos parâmetros da etapa anterior. O objetivo desse teste foi avaliar se as taxas de extração de líquido, substancialmente maiores que as esperadas, obtidas durante as etapas do ensaio-piloto, deviam-se a condições específicas do poço ou à aplicação do vácuo no cabeçote do mesmo.
$\mathrm{Na}$ área 2 foram conduzidos testes de TPE, bombeamento e DPE em dois poços existentes, com o objetivo de verificar se o comportamento observado nos ensaios da área 1 , particularmente as alterações significativas das vazões de extração de água subterrânea com a aplicação de vácuo, se confirmariam também para poços na área 2 , ou se tratava de uma condição específica do poço de extração utilizado.

Conforme informado anteriormente, as áreas 1 e 2 compreendem plumas de produto e de compostos de interesse ocasionadas pelo mesmo evento de vazamento.

$\mathrm{Na}$ área 2, foram aproveitadas as instalações do sistema TPE existente, alterando-se a posição do tubo extrator e acrescentadas bombas pneumáticas para o ensaio de DPE.

Nessa etapa dos testes foram monitorados os mesmos parâmetros da área 1: vazões de extração de água, de produto e de vapores; vácuo aplicado no sistema e nos cabeçotes do poço de extração e dos poços de observação; variação do nível d'água no poço de extração e nos poços de observação, utilizando transdutores de pressão; concentração expedita de VOCs nos vapores extraídos, medida com instrumentação portátil; concentração dos compostos de interesse (BTEX, TPH e PAH) nos efluentes líquidos por meio de análises químicas. Foi coletada uma amostra de efluente no final do teste.

Os equipamentos e instrumentos utilizados nos ensaios de campo nas áreas 1 e 2 são listados no Quadro 2. 
Comparação da eficiência das técnicas de bombeamento, TPE E DPE para remediação de áreas contaminadas por hidrocarbonetos de petróleo

Quadro 2 - Equipamentos, instrumentos e materiais utilizados nos ensaios de campo

Table 2 - Equipment, instruments and materials used in field tests

\begin{tabular}{|c|c|}
\hline COMPONENTE & $\begin{array}{c}\text { ESPECIFICAÇÃO TÉCNICA } \\
\end{array}$ \\
\hline Bomba de vácuo & Compressor Radial (Side Channel), motor $13,2 \mathrm{~kW}, 420 \mathrm{~m}^{3} / \mathrm{h}$ \\
\hline Bomba helicoidal de transferência & motor $1,5 \mathrm{~kW}$ \\
\hline Tanques metálicos. & Fabricados com chapas de aço de $3 \mathrm{~mm}$, pintados pelo processo eletrostático \\
\hline Painel Elétrico de Controle do Sistema TPE & $\begin{array}{l}\text { Proteções contra sobrecorrente e falta de fase, inversor de frequência, CLP, } \\
\text { IHM }\end{array}$ \\
\hline Caixa separadora de água e óleo & Tipo placas coalescentes, capacidade $2.000 \mathrm{l} / \mathrm{h}$ \\
\hline Filtro de carvão ativado para fase líquida & $\begin{array}{l}\text { Montado com plástico reforçado com fibra de vidro com capacidade nomi- } \\
\text { nal } 2001 .\end{array}$ \\
\hline Filtro de carvão ativado para fase gasosa & $\begin{array}{l}\text { Montado com plástico reforçado com fibra de vidro com capacidade nomi- } \\
\text { nal } 2001 .\end{array}$ \\
\hline Manômetros analógicos & Tipo Bourdon, escala $0-12 \mathrm{kgf} / \mathrm{cm}^{2}$ \\
\hline Vacuômetros analógicos & Tipo Bourdon, escala -1 a $0 \mathrm{kgf} / \mathrm{cm}^{2}$ \\
\hline Hidrômetro analógico & Vazão nominal $1,5 \mathrm{~m}^{3} / \mathrm{h}$, vazão mínima $30 \mathrm{l} / \mathrm{h}$ \\
\hline Chaves de nível baixo, alto e alto-alto & Tipo bois de inserção lateral, em polipropileno \\
\hline Bomba pneumática (2 unidades) & $\begin{array}{c}\text { Construída em aço inox } \begin{array}{c}316 \text {, diâmetro } 3,8 \mathrm{~cm} \text {, comprimento } 66 \mathrm{~cm} \text {, bocal } \\
\text { de captação } 6,6 \mathrm{~cm}\end{array} \\
\end{array}$ \\
\hline $\begin{array}{l}\text { Painel Elétrico de Controle de ar Compri- } \\
\text { mido }\end{array}$ & Duas entradas e 4 saídas, temporizador, válvulas reguladoras de pressão \\
\hline $\begin{array}{l}\text { Conjunto Fitro regulador, coalescente e car- } \\
\text { vão ativado para ar comprimido ( } 2 \text { unidades })\end{array}$ & Manômetros de 0 a 10 bar, 0,05 micras. \\
\hline Válvulas esfera & 1/2 polegada, em latão. \\
\hline Compressor de & $78,8 \mathrm{~m}^{3} / \mathrm{h}, 7 \mathrm{bar}$ \\
\hline Mangueiras de ar comprimido & Capacidade para 10 bar de pressão, diâmetro $3 / 8$ de polegada. \\
\hline Mangueiras de extração de água subterrânea & Mangueiras descartáveis em polietileno, diâmetro $1 / 8$ de polegada \\
\hline Caixas para coleta de efluentes líquidos & Caixas em polietileno, capacidade 54,3 litros. \\
\hline Balde graduado & Capacidade 30 litros \\
\hline Bateria & $\begin{array}{l}\text { Bateria de motocicleta, } 12 \mathrm{~V}, 6,5 \mathrm{~mA} \text {, para alimentação do painel de con- } \\
\text { trole de ar comprimido. }\end{array}$ \\
\hline Sistema de aquisição de dados SAD-TP & Equipado com 2 Fildlogger, 8 canais de entrada cada \\
\hline Transmissor de nível & $\begin{array}{c}\text { Faixa de } 0 \text { a } 1 \text { bar (10 m.c.a), sinal de saída } 4 \text { a } 20 \text { mA, alimentação } 10 \text { a } 30 \\
\text { VAC, número de série } 97879\end{array}$ \\
\hline Transmissor de nível & $\begin{array}{l}\text { Faixa de } 0 \text { a } 10 \text { m.c.a, sinal de saída } 4 \text { a } 20 \text { mA, alimentação } 10 \text { a } 30 \mathrm{VAC}, \\
\text { número de série } 09 / 2013\end{array}$ \\
\hline Transmissor de pressão & Faixa 0 a -1bar, no. de série: $2842 / 11$ alimentação 10 a 30 Vcc. \\
\hline Laptop & $\begin{array}{l}\text { Para instalação do software Fildlogger e acompanhamento visual do moni- } \\
\text { toramento de níveis de água e vácuo em tela, durante o ensaio. }\end{array}$ \\
\hline Detector de VOC's & Detector de Gases PID para VOC, faixa de 1 ppb a 20000 ppm \\
\hline Interface & ( \\
\hline
\end{tabular}

Fonte: Elaborado pela autora

\section{RESULTADOS E DISCUSSÃO}

O Quadro 3 apresenta o resumo dos volumes de água e de produto extraídos por quatro empresas de remediação que trabalharam na área, entre 2003 e 2014, com diferentes sistemas de remediação e as respectivas taxas de extração água/produto. 
Quadro 3 - Taxas de extração de produto ao longo da operação de diferentes sistemas de remediação implantados na área de interesse

Table 3 - Product extraction rates for different operating remediation systems in the area of interest

\begin{tabular}{|c|c|c|c|c|c|c|}
\hline $\begin{array}{l}\text { Empresa Res- } \\
\text { ponsável pela } \\
\text { Remediação }\end{array}$ & $\begin{array}{l}\text { Período de } \\
\text { Operação }\end{array}$ & $\begin{array}{l}\text { Tipos de Siste- } \\
\text { mas }\end{array}$ & $\begin{array}{l}\text { Número de Po- } \\
\text { ços de Bombea- } \\
\text { mento / Extra- } \\
\text { ção }\end{array}$ & $\begin{array}{c}\text { Volume Ex- } \\
\text { traído de } \\
\text { Água Subt. } \\
\quad\left(\mathrm{m}^{3}\right)\end{array}$ & $\begin{array}{l}\text { Volume de } \\
\text { Produto Ex- } \\
\text { traído }\left(\mathbf{m}^{3}\right)\end{array}$ & $\begin{array}{c}\text { Taxa de Extra- } \\
\text { ção Água/Pro- } \\
\text { duto }\end{array}$ \\
\hline \multirow{2}{*}{ Empresa 1} & $\begin{array}{c}\text { fevereiro/2003 a } \\
\text { fevereiro/2005 }\end{array}$ & Bombeamento & 4 & $1.816,50$ & 51,4 & $35,34: 1$ \\
\hline & $\begin{array}{c}\text { fevereiro/2004 a } \\
\text { fevereiro/2005 }\end{array}$ & Skimmer & 2 & - & 2,93 & - \\
\hline Empresa 2 & $\begin{array}{c}\text { outubro/2005 a } \\
\text { maio/2008 }\end{array}$ & TPE & 26 & $75.600,00^{(*)}$ & 71,8 & $1.053: 1$ \\
\hline \multirow{2}{*}{ Empresa 3} & \multirow{2}{*}{$\begin{array}{c}\text { novembro/2008 } \\
\text { a agosto/2010 }\end{array}$} & Bombeamento & 15 & \multirow{2}{*}{$2.439,76$} & \multirow{2}{*}{0,498} & \multirow{2}{*}{$4.899: 1$} \\
\hline & & TPE & 8 & & & \\
\hline \multirow{2}{*}{ Empresa 4} & \multirow{2}{*}{$\begin{array}{c}\text { junho/2011 a ju- } \\
\text { nho/2014 }\end{array}$} & Bombeamento & 10 & $1366,00^{(* *)}$ & 0,0036 & $379.444: 1$ \\
\hline & & TPE & 8 & $685,88^{(* *)}$ & 0,506 & $1.355,5: 1$ \\
\hline
\end{tabular}

(*) Volume estimado pela autora, com base na informação de vazão média de extração e tempo de operação. (**) Operação intermitente, $8 \mathrm{~h} /$ dia.

Fonte: dados de relatórios técnicos de empresas de remediação

O Quadro 4 apresenta a totalização dos volumes de água, produto e massa de contaminantes extraídos pelos sistemas de bombeamento e TPE, nas áreas 1 e 2 , respectivamente, no período compreendido entre outubro de 2011 e junho de 2014, época em que a quarta empresa de remediação assumiu os trabalhos na área e quando os sistemas implantados eram bastante semelhantes à configuração atual, e cujos equipamentos foram utilizados nos testes de campo. Em 5888 horas de operação no período considerado, as vazões médias de um poço de bombeamento e de um poço de TPE foram, respectivamente, de $20,96 \mathrm{~L} / \mathrm{h} \mathrm{e}$ $11,53 \mathrm{~L} / \mathrm{h}$.

O ensaio contínuo de campo na área 1 , utilizando a técnica de DPE, teve duração de
54 horas, nas quais foram extraídos $4,385 \mathrm{~m}^{3}$ de água subterrânea, resultando em uma vazão média de extração de $81,2 \mathrm{~L} / \mathrm{h}$; a vazão média de vapores extraídos foi de $128,7 \mathrm{~m}^{3} / \mathrm{h}$. O raio máximo de influência do vácuo aplicado foi de $15 \mathrm{~m}$, havendo diferenças nos distintos sentidos em relação ao poço de extração.

$\mathrm{O}$ teste de vazão para bombeamento e DPE na área 1, com duração de 2 horas cada um, resultou em vazão média de $96 \mathrm{~L} / \mathrm{h}$ para o ensaio de DPE e $59 \mathrm{~L} / \mathrm{h}$ para o ensaio de bombeamento, indicando portanto um aumento de $38,5 \%$ na vazão de extração de água subterrânea com a aplicação de vácuo no cabeçote do poço. 
Quadro 4 - Resumo dos Parâmetros para Comparação dos Sistemas de Bombeamento e TPE - período de outubro de 2011 a junho de 2014

Table 4 - Summary of parameters obtained from Pumping Systems and TPE - period of october 2011 to June 2014

\begin{tabular}{|l|c|c|}
\hline \multicolumn{1}{|c|}{ PARÂMETROS } & $\begin{array}{c}\text { BOMBEAMENTO } \\
\text { (ÁREA 1) }\end{array}$ & $\begin{array}{c}\text { TPE } \\
\text { (ÁREA 2) }\end{array}$ \\
\hline Volume de produto extraído (L) & 5,5 & 361,0 \\
\hline Volume de água subterrânea extraída $\left(\mathrm{m}^{3}\right)$ & $1.233,9$ & 543,0 \\
\hline Massa de contaminantes extraída em fase dissolvida (g) & $1.344,3$ & $37.222,2$ \\
\hline Taxa global de extração água/óleo & $\mathbf{2 2 4 . 3 4 4 : \mathbf { 1 }}$ & $\mathbf{1 . 5 0 4 : \mathbf { 1 }}$ \\
\hline
\end{tabular}

Fonte: Elaborado pela autora com dados de relatórios de operação de empresas de remediação

O Quadro 5 apresenta os resultados obtidos no teste de TPE realizado na área 2. Observações importantes durante o ensaio, com relação à aparência da fase líquida extraída, foram forte odor, coloração âmbar e brilho característico da presença de óleo na superfície. Os resultados das vazões obtidas durante o ensaio de bombeamento na área 2 são apresentados no Quadro 6. O Quadro 7 apresenta as vazões médias diárias de extração de líquidos obtidas durante o ensaio de DPE na área 2 e as condições de operação do teste. Os efluentes coletados no teste de DPE apresentaram iridescência, forte odor e gotículas de óleo sobrenadante, indicando um processo de remoção de contaminantes possivelmente melhor que o TPE. As vazões de extração de líquidos na área 2, obtidas com a utilização das três técnicas, TPE, bombeamento e DPE, são sumariadas no Quadro 8.

Quadro 5 - Vazões de Extração de Líquidos no Ensaio TPE - área 2

Table 5 - Extraction rate of TPE test - Area 2

\begin{tabular}{|c|c|c|c|c|c|c|}
\hline Data & $\begin{array}{c}\text { Vácuo aplicado no } \\
\text { sistema (mmHg) }\end{array}$ & $\begin{array}{c}\text { Vácuo no cabeçote } \\
\text { dos Poços (mmHg) }\end{array}$ & Volume (L) & $\begin{array}{c}\text { Poço de Ex- } \\
\text { tração }\end{array}$ & $\begin{array}{c}\text { Horas de en- } \\
\text { saio }\end{array}$ & $\begin{array}{c}\text { Vazão mé- } \\
\text { dia (L/h) }\end{array}$ \\
\hline $09 / 12 / 2014$ & 240 & 0,63 & 129 & PE-01 & 5 & 25,80 \\
\hline $10 / 12 / 2014$ & 230 & 6,96 & 65 & PM-28 & 4 & 16,13 \\
\hline
\end{tabular}

Fonte: Elaborado pela autora

Quadro 6 - Vazões de Extração de Líquidos no ensaio de Bombeamento - área 2

Table 6 - Extraction rate of pumping test - Area 2

\begin{tabular}{|c|c|c|c|c|}
\hline Data & Poço & Tempo de ensaio (h) & Volume (L) & Vazão Média (L/h) \\
\hline \multirow{2}{*}{$11 / 12 / 2014$} & PE-01 & 4 & 104 & 26 \\
\cline { 2 - 5 } & PM-28 & 4 & 54 & 13,5 \\
\hline \multirow{2}{*}{$12 / 12 / 2014$} & PE-01 & 3,16 & 70 & 22,15 \\
\cline { 2 - 5 } & PM-28 & 3,16 & 39,5 & 12,50 \\
\hline \multirow{2}{*}{$15 / 12 / 2014$} & PE-01 & 2 & 48 & 24,00 \\
\cline { 2 - 5 } & PM-28 & 2 & 38 & 19,00 \\
\hline
\end{tabular}

Fonte: Elaborado pela autora

Quadro 7 - Vazões médias de extração de líquidos obtidas durante o ensaio de DPE na área 2

Table 7 - Average extraction rate obtained during the DPE test in area 2

\begin{tabular}{|c|c|c|c|c|c|c|c|}
\hline \multirow{2}{*}{ Data } & $\begin{array}{c}\text { Vácuo aplicado no } \\
\text { sistema (mmHg) }\end{array}$ & $\begin{array}{c}\text { Poço de } \\
\text { Extração }\end{array}$ & $\begin{array}{c}\text { Vácuo médio no cabe- } \\
\text { çote dos Poços } \\
\text { (mmHg) }\end{array}$ & $\begin{array}{c}\text { Rebaixamento } \\
\text { médio do NA } \\
(\mathbf{m})\end{array}$ & $\begin{array}{c}\text { Tempo } \\
\text { de ensaio } \\
(\mathbf{h})\end{array}$ & $\begin{array}{c}\text { Vo- } \\
\text { lume } \\
(\mathbf{L})\end{array}$ & $\begin{array}{c}\text { Vazão } \\
\text { média } \\
(\mathbf{L} / \mathbf{h})\end{array}$ \\
\hline \multirow{2}{*}{$17 / 12 / 2014$} & \multirow{2}{*}{230} & PE-01 & 7,56 & 0,58 & 1,13 & 48 & 42,48 \\
\cline { 2 - 8 } & & PM-28 & 37,37 & 0,09 & 1,13 & 36 & 31,86 \\
\hline \multirow{2}{*}{$18 / 12 / 2014$} & \multirow{2}{*}{200} & PE-01 & 4,32 & 0,582 & 4,17 & 180 & 43,05 \\
\cline { 2 - 8 } & & PM-28 & 30,50 & 0,04 & 4,17 & 124 & 29,74 \\
\hline
\end{tabular}

Fonte: Elaborado pela autora 
Quadro 8 - Comparação das vazões de extração de água subterrânea pelas técnicas de bombeamento, TPE e DPE na área 2

Table 8 - Comparison of groundwater extraction rate for pumping, TPE and DPE technics in area 2

\begin{tabular}{|c|c|c|c|c|}
\hline Sistema & $\begin{array}{c}\text { Vazões no PE-01 } \\
(\mathrm{L} / \mathrm{h})\end{array}$ & $\begin{array}{c}\text { Vazões médias por } \\
\text { processo no PE-01 } \\
(\mathrm{L} / \mathrm{h})\end{array}$ & $\begin{array}{c}\text { Vazões no PM-28 } \\
(\mathrm{L} / \mathrm{h})\end{array}$ & $\begin{array}{c}\text { Vazões médias por } \\
\text { processo no PM-28 } \\
(\mathrm{L} / \mathrm{h})\end{array}$ \\
\hline TPE & 25,80 & 25,80 & 16,13 & 16,13 \\
\hline \multirow{3}{*}{ Bombeamento } & 26,00 & \multirow{3}{*}{24,05} & 13,50 & \multirow{3}{*}{15,00} \\
\hline & 22,15 & & 12,50 & \\
\hline & 24,00 & & 19,00 & \\
\hline \multirow{2}{*}{ DPE } & 42,48 & \multirow{2}{*}{42,77} & 31,86 & \multirow{2}{*}{30,80} \\
\hline & 43,05 & & 29,74 & \\
\hline
\end{tabular}

Fonte: Elaborado pela autora

Apesar das incertezas envolvidas nos dados, observando-se o Quadro 3 é possível verificar que a taxa de remoção de produto foi muito maior no início da operação em 2003, comparadas às taxas nos períodos subsequentes, independentemente da técnica de remediação utilizada. Este comportamento pode ser atribuído à existência inicial de espessuras de fase livre superiores a $2 \mathrm{~m}$, condição favorável à extração do óleo por bombeamento ou por outras técnicas, como skimmer e TPE. Atualmente, a espessura de fase livre é inferior a 2 $\mathrm{cm}$, o que dificulta a remoção por essas técnicas.

A redução da espessura de produto na área ocorreu não apenas devido à operação dos sistemas de remediação ao longo dos anos, mas também pelo espalhamento da pluma e pela distribuição da contaminação para outras fases (fase dissolvida, fase gasosa, fase residual em solo).

Comparando-se as taxas médias de extração água/óleo, obtidas de outubro de 2011 a junho de 2014 para o sistema de bombeamento na área 1 (244 344:1) e para o sistema TPE na área 2 (1244:1), conclui-se que o sistema TPE foi muito mais eficiente na remoção de fase livre que o bombeamento. Este fato que pode ser explicado não apenas pelo aumento do gradiente causado pela aplicação de vácuo na técnica TPE, mas pela extração na interface água - óleo, prioriza a remoção da fase oleosa em relação à água subterrânea, sem causar um rebaixamento significativo no aquífero.

Os volumes de óleo extraídos pelos dois sistemas no mesmo período de operação (outubro de 2011 a junho de 2014) foram de $5,5 \mathrm{~L}$ no bombeamento e $361 \mathrm{~L}$ no TPE. As vazões médias de um poço de bombeamento e de um poço de TPE foram, respectivamente, de $20,96 \mathrm{~L} / \mathrm{h}$ e $11,53 \mathrm{~L} / \mathrm{h}$, no período considerado.

Embora as vazões de água subterrânea extraídas fossem muito maiores no sistema de bombeamento (volume total: $1.233,9 \mathrm{~m}^{3}$ ) que no sistema TPE (volume total: $543 \mathrm{~m}^{3}$ ), as concentrações dos compostos de interesse foram substancialmente maiores nos efluentes do sistema TPE, resultando em uma maior extração em massa dos compostos de interesse BTEX e TPH (37 222,2 g) quando comparada com a extração de massa obtida pelo bombeamento (1344,3 g). As Figuras 5 e 6 apresentam as comparações de massa dos contaminantes removidos em fase dissolvida e em fase livre, respectivamente, pelos dois sistemas, no período de 2011 a 2014.

Portanto, o sistema TPE foi mais eficiente que o bombeamento tanto na extração de produto quanto na remoção de massa dos compostos de interesse em fase dissolvida, sem contabilizar a massa removida em fase vapor e a massa removida por biorremediação, estimulada pela maior ventilação do meio causada pela aplicação de vácuo. 
Comparação da eficiência das técnicas de bombeamento, TPE E DPE para remediação de áreas contaminadas por hidrocarbonetos de petróleo

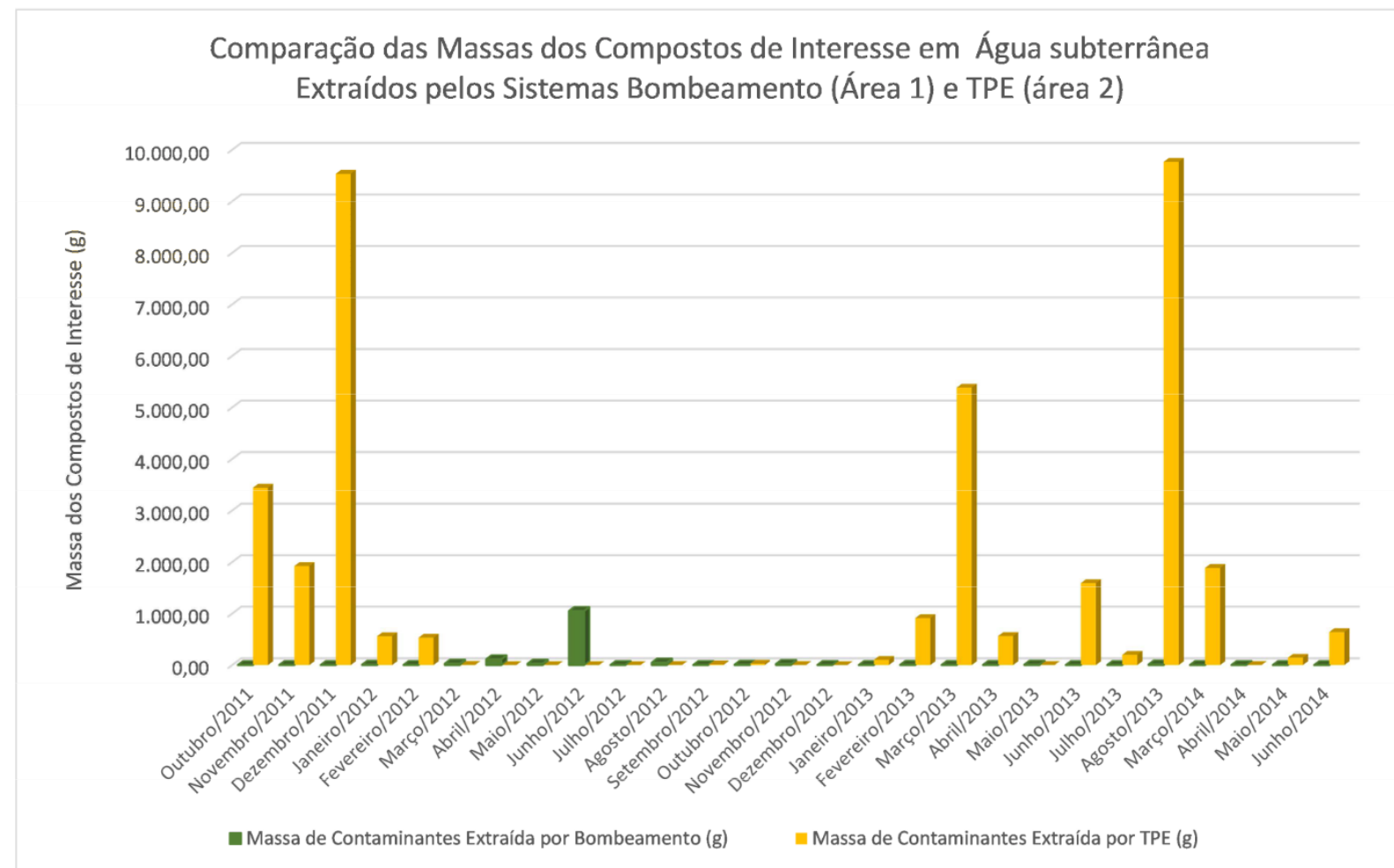

Figura 5 - Comparação das massas de compostos de interesse em água subterrânea (Fase dissolvida) extraídos pelo sistema de bombeamento (área 1) e TPE (área 2)

Figure 5 - Comparison of masses of compounds of interest in groundwater (dissolved phase) extracted by the pumping system (area 1 ) and TPE (area 2 )

Fonte: Elaborado pela autora com dados de relatórios de operação de empresas de remediação

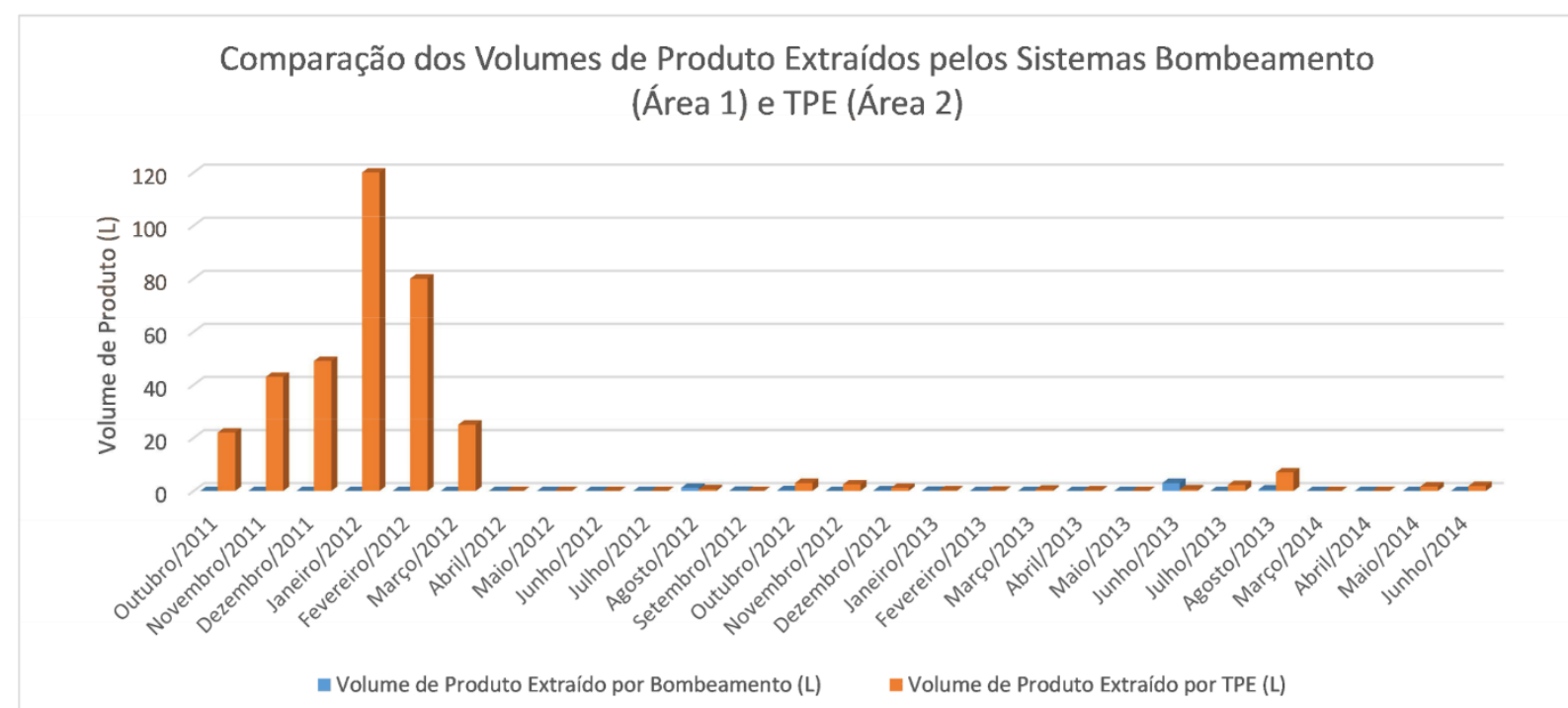

Figura 6 - Comparação dos Volumes de Produto Extraídos (Fase livre) pelos Sistemas de Bombeamento (área 1) e TPE (área 2)

Figure 6 - Figure 6 - Comparison of Extracted Product Volumes ( free phase) by Pumping Systems ( Area 1 ) and TPE (area 2 )

Fonte: Elaborado pela autora com dados de relatórios de operação de empresas de remediação

A área em estudo apresenta fluxo preferencial no sentido sudeste-noroeste, e nessa direção os rebaixamentos obtidos nos poços de observação foram progressivamente maiores. Embora coincidente com a direção preferencial de fluxo, este comportamento também 
pode indicar a presença de heterogeneidades, associada à diferença de litologias presentes na área. No sentido preferencial de fluxo, a zona de influência na área 1 alcançou mais de $15,0 \mathrm{~m}$.

As concentrações dos compostos de interesse nos testes da área 1 foram muito maiores na fase líquida que na gasosa, o que é esperado para compostos como o diesel, que possuem menor quantidade de voláteis em sua composição quando comparados à gasolina, por exemplo. De forma geral, quanto mais volátil for o contaminante maior será a concentração na fase vapor.

Não foi possível contabilizar a fase livre extraída no teste, pois havia uma pequena espessura inicialmente no poço de extração, e o óleo recuperado ficou emulsionado na água subterrânea e aderido às paredes e placas corrugadas da caixa-separadora água-óleo do sistema.

O teste de vazões para bombeamento e DPE na área 1 resultou em um aumento de $38,5 \%$ na vazão de extração de água subterrânea com a aplicação de vácuo no cabeçote do poço, comparada com o bombeamento simples. Considerando apenas a vazão de extração de líquido, o teste na área 1 demonstrou maior eficiência do DPE em relação ao bombeamento.

Comparando-se as vazões médias obtidas no ensaio de TPE na área 2, nos poços de extração PE-01 e PM-28 (25,8 L/h e 16,13 $\mathrm{L} / \mathrm{h}$, respectivamente), com as vazões médias de extração no período de outubro $(16,7 \mathrm{~L} / \mathrm{h})$ e novembro de $2014(17,8 \mathrm{~L} / \mathrm{h})$ nos mesmos poços, nota-se que, durante o ensaio realizado na área 2, a vazão de extração no PE-01 foi $45 \%$ maior que a média em novembro e $124 \%$ maior que a média nos anos de 2011 a 2014. No PM-28, apesar da vazão ter sido inferior à média de novembro, foi $39,9 \%$ maior que a média das vazões de operação no período de 2011 a 2014.

Esse aumento das vazões de extração pode ser explicado provavelmente pelo aumento de vácuo aplicado ao cabeçote dos poços durante o ensaio, comparado ao vácuo aplicado durante a operação normal do sistema.

$\mathrm{O}$ ensaio de bombeamento na área 2 indicou vazão média de extração de líquido de $24 \mathrm{~L} / \mathrm{h}$ para o PE-01 e de $15 \mathrm{~L} / \mathrm{h}$ para o PM28. A coluna de líquido acima do bocal de captação da bomba era de 1,293 m no PE-01 e de apenas 0,506 m no PM-28, o que pode explicar as maiores vazões obtidas no PE-01, comparadas as do PM-28.

No ensaio de DPE realizado na área 2 foram obtidas vazões médias de extração de líquido de 42,77 L/h no PE-01 e de $30,8 \mathrm{~L} / \mathrm{h}$ no PM-28. Não foi possível medir a quantidade de produto extraída ao longo do ensaio, porém, os efluentes coletados nas caixas coletoras utilizadas apresentaram iridescência, forte odor e gotículas de óleo sobrenadante. Esta característica, apesar de qualitativa, é indicador de que a técnica é mais eficiente do que as demais, porque mobilizou LNAPL (mesmo que em gotículas), fato que não ocorreu no teste das demais variações da técnica.

Os resultados obtidos nos testes realizados na área 2 (Quadro 8 e Figura 7) mostram um aumento significativo na vazão de extração de líquidos quando se utilizou o sistema DPE, em relação aos valores obtidos nos mesmos poços com as técnicas de TPE e bombeamento. Para o PE-01, a vazão média de extração com DPE foi 39,68 \% maior que a vazão no TPE e 43,77 \% maior que no bombeamento. Notou-se também pouca diferença nas vazões obtidas com bombeamento e TPE. 


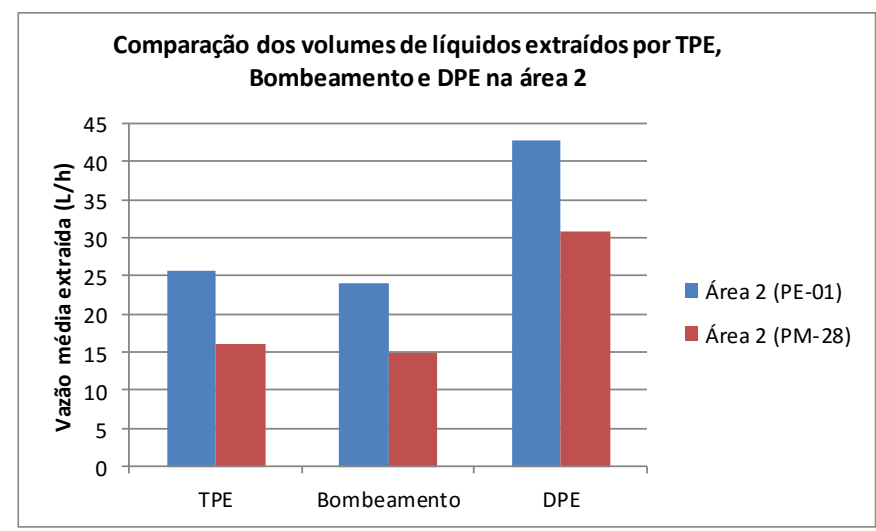

Figura 7- Comparação dos volumes de líquidos extraídos por TPE, Bombeamento e DPE na área 2 Figure 7 - Comparison of volumes of liquids extracted by TPE, Pumping and DPE in area 2 Fonte: Elaborado pela autora

Para o PM-28, a vazão média de extração obtida com DPE foi 47,63 \% maior em relação ao TPE e 51,30 \% maior em relação ao bombeamento. Como as bombas no ensaio de DPE operaram exatamente nas mesmas condições que no ensaio de bombeamento, sendo mantidas as mesmas posições no interior dos poços, mesma pressão de ar comprimido, mesmo intervalo de injeção de ar comprimido e tempos de operação semelhantes, o incremento observado nas vazões de extração estão fortemente correlacionados à aplicação do vácuo nos cabeçotes dos poços.

Outra observação importante é que os vácuos aplicados aos cabeçotes dos poços foram praticamente iguais nos ensaios de TPE e DPE e, no segundo caso, as vazões de extração foram substancialmente maiores.

Dessa forma, conclui-se que a aplicação de vácuo no cabeçote dos poços juntamente com o bombeamento, que constitui a prática da aplicação da técnica DPE, é responsável pelo aumento nas vazões de extração, fato que foi igualmente observado no teste-piloto realizado na área 1, em que o poço de extração PM-15 apresentou vazões de extração de líquido 39,9\% maior com o DPE quando comparado ao bombeamento simples nas mesmas condições de ensaio, valor bastante similar ao observado nos testes da área 2.

O aumento da vazão de água observada nos testes de DPE nas áreas 1 e 2 pode ser explicado pelo aumento do gradiente de pressão causado pela aplicação do vácuo e este resultado é compatível com a previsão teórica, considerando a Lei de Darcy (equa- ção 11). De acordo com esta equação, o aumento do gradiente de pressão aplicado ao poço seria transmitido para cada uma das fases i e causaria o aumento do fluxo em direção ao poço. Dessa forma, a previsão teórica foi confirmada pelos resultados obtidos nos testes.

O aumento na taxa de extração de óleo não pôde ser observado nos ensaios realizados, provavelmente devido à pequena espessura de óleo predominante no cenário de contaminação no momento dos testes. No entanto, a equação de Hubbert (equação 7) e a equação 10 mostram que a migração de óleo é influenciada pelo gradiente hidráulico associado ao movimento da água, no caso dos efeitos da pressão capilar poderem ser desprezados. Essa condição poderia ser assumida particularmente para a área 2, onde os níveis d'água são rasos. Dessa forma, como houve um aumento significativo da vazão de extração de água, presume-se que ocorreria também um aumento significativo na vazão de extração de óleo, caso sua espessura fosse maior durante a realização dos testes.

\section{CONCLUSÃO}

A compilação de dados de sistemas de remediação em operação desde 2003 e de dados dos ensaios de campo realizados em 2014, foi possível confirmar o aumento significativo das vazões de extração utilizando a técnica de DPE em relação às vazões obtidas com as técnicas de bombeamento e TPE.

Para a área 1, a utilização do DPE re- 
sultou em vazão de extração de líquido 38,5\% maior que a obtida por bombeamento. Nos testes realizados na área 2, a utilização do DPE no poço de extração PE-01 resultou em aumentos de $39,68 \%$ na vazão de líquido em relação ao TPE e de $43,77 \%$ em relação ao bombeamento. Já para o poço PM-28, a vazão média obtida com o DPE foi 47,63\% maior em relação ao TPE e 51,3\% maior em relação ao bombeamento.

A maior eficiência do DPE em relação às outras técnicas ensaiadas, evidenciada nos ensaios de campo, pode ser explicada pela maior exposição da zona saturada ao gradiente de pressão aplicado, pois o rebaixamento causado pelo bombeamento permite a maior drenagem de uma porção anteriormente saturada com água.

Recomenda-se a utilização de processos contínuos de operação em detrimento à

\section{REFERÊNCIAS}

BRASIL.CETESB, Companhia de Tecnologia de Saneamento Ambiental. Manual de Gerenciamento de Áreas Contaminadas. São Paulo: CETESB, 2001. Disponível em: <http://www.cetesb.sp.gov.br/areascontaminadas/manual-de-gerenciamento-de-areascontaminadas/7-manual-de-gerenciamento-das--acs $>$. Acesso em: 16 jun. 2015.

CHARBENEAU, Randall J. Groundwater Hydraulics and Pollutant Transport. $1^{\text {th }}$ Ed. Long Grove: Waveland Press, 2006. 589p.

CHARBENEAU Randall J. Groundwater Hidraulics and Pollutant Transport,.EPA United States environmental Protection Agency. Superfund Remedy Report - 14th Edition. EPA 542-R-13-016. 2013. 44p.

CHARBENEAU, Randall. LNAPL Distribution and Recovery Model (LDRM) Media. Austin: API, 2007. 68p. (API PUBLICATION 4760). Disponível em <http://www.api.org/environment-health-and safety/cleanwater/groundwater/lnapl/ /media/Files/EHS/Clean_Water/Ground_Water_Quality/LNAPL/4760-v1.pdf>. Acesso em 16 jun. 2015.

CHARBENEAU, Randall. LNAPL Distribution and Recovery Model (LDRM) Volume 1: Distribution and Recovery of Petroleum Hydrocarbon Liquids in Porous Media. API PUBLICATION 4760. 2007. 68p. Disponível em: <http://www.api.org/environment-health-and safety/cleanwater/groundwa- operação intermitente, mantendo-se o rebaixamento nos poços praticamente constante, de forma que os processos de embebição e drenagem sejam minimizados, pois mantendo a drenagem na porção rebaixada e expondo-a continuamente ao vácuo, a porção recuperável de óleo poderá fluir mais facilmente para os poços. Além disso, a operação contínua favorece a maior aeração do meio e estimulação de processos de oxidação biológica dos compostos orgânicos no meio impactado.

Dessa forma é possível concluir que o DPE é uma alternativa de remediação viável para áreas contaminadas por hidrocarbonetos de petróleo, pois, apesar de apresentar maior custo de implantação em relação a outras técnicas, pode proporcionar aumentos significativos nas vazões de extração e consequente redução do tempo para que os objetivos da remediação sejam atingidos.

ter/lnapl/ /media/Files/EHS/Clean_Water/Ground_Water_Quality/LNAPL/4760-v1.pdf> Acesso em: 14 jun.2015

ESTADOS UNIDOS.EPA, Environmental Protection Agency.. Coast andPerformance Report for LNAPL Recovery - Multi-Phase Extraction and Dual-Pump Recovery of LNAPL at the BP Former Amoco Refinery, Sugar Creek, MO. [S.I.] Environmental Protection Agency, 2005. 47p. (EPA 542-R-05-016). Disponível em: < http://www.epa.gov/superfund/remedytech/pubitech.htm> Acesso em: 14 jun. 2015.

ESTADOS UNIDOS. EPA, Environmental Protection Agency. Presumptive Remedy: Supplemental Bulletin Multi-Phase Extraction (MPE) Technology for VOCs in Soil and Groundwater.[S.I.]: EPA, 1997. 11p. (EPA 540-F-97-004). Disponível em: <http://www.clu-in.org/download/toolkit/finalapr.pdf>. Acesso em: 14 jun. 2015.

ESTADOS UNIDOS. U.S. Army Corps of Engineers. Engineering and Design Multi-Phase Extraction. $1^{\text {th }}$ ed. Washington, D.C.: Environmental Protection Agency, 1999. 286p. (EM-1110-1-4010). Disponível em:

<http://www.publications.usace.army.mil/Portals/76/Publications/EngineerManuals/ EM 1110-14010.pdf > . Acesso em: 14 jun.2015.

ESTADOS UNIDOS. U.S. Army Corps of Engineers. Engineering and Design Multi-Phase Extraction. $1^{\text {th }}$ ed. Washington, D.C.: Environmental Protection 
Comparação da eficiência das técnicas de bombeamento, TPE E DPE para remediação de áreas contaminadas por hidrocarbonetos de petróleo

Agency, 1999. 286p. (EM-1110-1-4010). Disponível em:

<http://www.publications.usace.army.mil/Portals/76/Publications/EngineerManuals/ EM_1110-1-

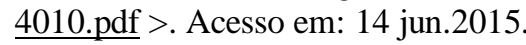

FETTER, C.W. Applied Hydrogeology. $3^{\text {rd }}$ ed. New York.: Macmillan College Publishing, Inc.,1994. , 616 $\mathrm{p}$

MACHADO, Marcely F. e SILVA, Sandra F. Geodiversidade do Estado de Minas Gerais. [S.I.]. CPRM, 2010. 131p. Disponível em :

<http://www.cprm.gov.br/publique/media/Geodiversidade MG.pdf $>$ Acesso em: 14 jun. 2015.

McDOWELL, A.Scott. and BARBEE, Gibson V. Re- moval of Petroleum Using Dual Phase Extraction.AREMA Conference, 2001. 22p. Disponível em:. <https://www.arema.org/files/library/2001_Conference_Proceedings/00047.pdf $>$. Acesso em: 14 jun. 2015.

RUZSIN, Thomas E. Dual Phase System Design Pilot Study Report - Gasoline Fueling Station - Royal Farms \#96 - AEC Project Number: 05-056 RF096. Advantage Environmental Consultants, LLC (AEC), 2012.124p.

SOLC, Jaroslav. JV Task 59 - Demosntration of Accelerated In Situ Contaminant Degradation vy Vacuum-Enhanced Nutrient Distribution. US Department of Energy, Report 2007-EERC-04-08. 2007. $74 \mathrm{p}$. 